\title{
ARROLAMENTO DAS FONTES HISTÓRICAS . DE MOGI DAS CRUZES - ESTADO DE SÃO PAULO.
}

\section{INTRODUÇÃO (*).}

O município de Mogi das Cruzes está situado no traçado da E. F. C. B., entre São Paulo e Rio de Janeiro.

Distante de São Paulo, em linha reta, 45 quilômetros, faz limites com Guarulhos, Santa Isabel, Suzano, Poá, Santos, Salesópolis, Guararema e Jacareí. Suas coordenadas geográficas são: latitude sul: $23^{\circ}, 31^{\prime} 24^{\prime}$; longitude W. Gr. $46^{\circ}, 11^{\prime}$ 42". A altitude é de 760 metros acima do nível do mar.

Cumpre-nos antes de passarmos a nôvo item de nossa exposição esclarecer o seguinte fato: embora Mogi das Cruzes seja constantemente incluída como uma cidade pertencente. ao Vale do Paraíba, realmente ela pertence ao Vale do Tietê, rio que corta as terras do município. E' preciso que se desfaça o eqüívoco, colocando-se o vizinho município da capital dentro do sistema fluvial ao qual êle realmente pertence.

\section{I. - BREVE HISTÓRICO.}

Mogi das Cruzes surgiu dentro dos limites da sesmaria concedida a Braz Cubas, em data discutida: 1560 para alguns historiadores, para outros a última década do século XVI (1); alguns outros ainda querem que seja o ponto inicial da existência da cidade a data de 1611 , sendo elevada a vila por provisão de D. Luís de Sousa, passada em 18 de agôsto de 1611.

(*). - Dados colhidos na Enciclopédia dos Munfcíplos, vol. XXLX, publicaçāo do Instituto Brasileiro de Geografia e Estatística. Rio de Janeiro, dezembro de 1957; Ferpeira (Eḿlio), Mogi das Cruzes - Jados Históricos e Notas Diversas. 1935.

(1). - Estamos de acôrdo com esta últịma hipbtese, defendida por D. Leopoldo, in Notas de História Eclesiástica, conforme indicaçăo de Jair Rocha Batalha, no seu trabalho, Gaspar Vaz, o fundador de Mogi das Cruzes, na Conquista do Guairá, inserido em sua obra Calhaus e Burgans, às páginas 44 e 45, em notas de rodapé. 
A $10^{\circ}$ de setembro do mesmo ano Gaspar Conqueiro, capitãomor da Capitania de São Vicente, levantou pelourinho.

Ocupou Mogi das Cruzes papel importante na colonização do Brasil (2), sendo encontrados muitos mogianos nas bandeiras que percorreram o Vale do Paraíba e sendo também dos primeiros a demandarem as imediações do Paranapanema.

Compreendia, ao tempo do Império, as paróquias de Santa Ana de Mogi das Cruzes, Nossa Senhora da Ajuda de Itaquaquecetuba, Senhor do Bom Jesus de Arujá e Nossa Senhora da Escada, as quais atualmente correspondem os municípios de Suzano, Poá, Ferraz de Vasconcelos, Itaquaquecetuba, Guararema e o distrito de Arujá e Freguesia da Ajuda, êstes pertencentes ao município de Santa Isabel.

Localizada como está, entre São Paulo e Rio de Janeiro, constituiu sempre pasagem obrigatória a todos quantos se destinavam às duas capitais. $O$ próprio imperador Pedro I, muitas vêzes, parou em Mogi das Cruzes. Numa de suas jornadas por São Paulo e parada forçada em Mogi das Cruzes, deixou uma bandeira imperial, verdadeira relíquia, guardada com todo o carinho pelos cidadãos mogianos (3) .

Elevada à categoria de município em 13-III-1855, compõe - mesmo, atualmente, os seguintes distritos: Mogí das Cruzes (sede), Biritiba Mirim, Sabauna, Taiaçupeba, Jundiapeba (ex-Santo Angelo) e Braz Cubas.

A história do município ainda está por se fazer. As fontes que iremos indicar, neste nosso trabalho, guardam em seus documentos, que remontam ao século XVII, muitas informações preciosas, à espera do pesquisador sagaz e paciente, que se preocupe em desvendar os mistérios dos arquivos, em muitos casos mal conservados, em outros cuidadosamente tratados, mas todos fàcilmente utilizáveis.

$\mathrm{E}^{\prime}$ pena que muitos documentos se tenham extraviado, conforme fomos informados e que muitos arquivos estejam para serem reorganizados, e se tenham perdido também muita coisa por mudanças ou por falta de cuidado de funcionários de épocas passadas, os quais pouco se preocupavam com o pas-

(2). - Veja-se, para confirmação desta nossa assertiva D. Leopłoldo, Notas da História Ecleslástica, 1939. Emprêsa Gráfica da Revista dos Tribunais, São Paulo, nas quais encontramos às páginas 70,72 e 73, indicaçōes de posse e renovação de posse de terras de São Bento de Sapucaí, com o que procuramos concatenar êstes arrolamentos de fontes com os daquele município, publicados na Revista de História n.o 45 (janeiro-março de 1961).

(3). - Freire (Manuel de Mello), Histórias da Historla de Mogi das Cruzes, as páginas 73 e segs., narra uma das estadas de D. Pedro em Mogi. Publlcaçåo Saraiva Editôra. São Paulo, 1958. 
sado histórico, considerando-o como coisa inútil ou "muito velha" para ser conservada.

\section{II. - ARQUIVO PAROQUIAL.}

\section{a). - Convento do Carmo.}

Localização: Largo do Carmo, s/n.

Neste convento encontra-se um dos mais pacientes pesquisadores de nossa cidade, quiçá de nosso Estado e mesmo do Brasil. E' êle frei Thimotheo Van Den Broock, culto frade carmelita, fonte inesgotável de conhecimentos de Mogi Antiga, e mesmo de todo o Estado de São Paulo.

8

o Convento do Carmo retém em seus arquivos farta documentação histórica, que remonta ao ano de 1627 , data em que se instalaram os frades carmelitas em nossa cidade. Desde o século XVII, portanto, até a data de hoje, pode o historiador encontrar documentos, não só do município, mas dos. municípios vizinhos, de inestimável valor.

O acesso à documentação não é difícil, desde que o pesquisador procure Frei Thimotheo, paciente e sempre disposto a ajudar, principalmente aos jovens, o qual além de orientar aquêle que busca esclarecimentos é em si próprio, uma enciclopédia de conhecimentos a respeito de Mogi das Cruzes, conhecendo os seus pormenores como a própria palma da mão.

Constituem, portanto, o arquivo do Carmo e frei Thimotheo Van Den Broock, a nosso ver, as fontes mais preciosas. sôbre o município de Mogi das Cruzes.

\section{b). - Igreja Matriz de Sant'Anna.}

Localização: Praça Cel. Benedito de Almeida, s/n. Vigário Cônego Roque Pinto de Barros.

Os livros mais importantes que o arquivo da Igreja Matriz de Mogi das Cruzes possui são os livros do Tombo, entretanto, sòmente os mais recentes se encontram arquivados na referida Igreja, uma vez que os mais antigos estão recolhidos à Cúria, em São Paulo, de modo que esta se constitui em preciosa fonte para o estudo do município de Mogi das Cruzes.

A consulta aos livros existentes na Igreja Matriz é facilitada pelo vigário, responsável pela paróquia. 


\section{III. - ARQUIVO DA PREFEITURA MUNICIPAL.}

Localização: Rua José Bonifácio, 370 .

Prefeito: Rodolpho Jungers (1960 a 1963).

Diretor Administrativo: Prof. Argeu Batalha (de 1938 a 1961).

O arquivo da Prefeitura Municipal encontra-se atualmente em fase de reorganização, existindo grande quantidade de documentos interessantes sôbre o município, bem como sôbre as relações intermunicipais e mesmo interestaduais.

O Diretor Administrativo, elemento vinculado à Prefeitura desde 1938 é o homem que mais conhece os documentos existentes dentro da mesma, sendo portanto elemento indispensável no caso de uma pesquisa vir a ser realizada nos arquivos da mesma.

Existe ainda, na Prefeitura, completamente organizado e em dia, o Arquivo do Departamento Administrativo, colocado à disposição de todos aquêles que desejem consultá-lo.

Acresce ainda que a consulta aos arquivos da Prefeitura é facilitada, tendo-se em vista a gentileza dos funcionários que nos atenderam, estando todos prontos a colaborar com os estudiosos da História.

\section{IV. - ARQUIVO DA CAMARA MUNICIPAL.}

Localização: Rua Dr. Corrêa, s/n. Edifício I de Setembro. Presidente da Câmara: Oswaldo Regino.

Vice-Presidente: Tufy Elias Andery.

Diretor-Secretário: Darcy Nogueira.

O arquivo da Câmara, no período anterior a 1948, está incompleto. Isto se deve principalmente ao fato da Câmara funcionar em edifício anexo à Prefeitura e, quando da mudança, muitos códices se extraviaram.

Fomos informados pelo Diretor-Secretário que, embora não esteja completo o arquivo, existem documentos datando de 1616, cinco anos depois da elevação do povoado à vila, material de valor inestimável, embora de difícil leitura, dado o péssimo estado de conservação em que se encontra.

A partir do ano de 1948 o arquivo se encontra muito bem organizado e perfeitamente em dia.

$O$ acesso ao arquivo é facilitado. 


\section{V. - ARQUIVOS DOS CARTÓRIOS DA COMARCA.}

a). - Cartório do $10^{\circ}$ Ofício e $10^{\circ}$ Tabelionato.

Localização: Rua José Bonifácio, 360.

Tabeliāo: Professor Benedicto L. Arouche de Toledo.

Data da instalação: 1700 .

O arquivo do cartório se encontra em ótimas condições.

O mais antigo maço de documentos data do ano de 1795 .

Quanto ao acesso à documentação, facilitada em todos os pontos, uma vez que o tabelião Professor Benedicto Arouche de Toledo é cordialíssimo e está sempre pronto a colaborar com todos aquêles que se interessem pelos assuntos relacionados com a História.

b). - Cartório do 2. Ofício e 2.० Tabelionato.

Localização: Rua Dr. Paulo Frontin, 96.

Tabelião: Manuel de Souza Melo Freire.

Data da instalação: 1912 .

$O$ arquivo dêste cartório encontra-se totalmente conservado, existindo nêle, segundo o tabelião Melo Freire, documentação histórica interessantíssima e sendo o documento mais antigo ali depositado do ano de 1616, um inventário de João dos Santos, sendo inventariante João Martins.

A consulta ao arquivo dêste cartório é facilitada, sendo cordial a acolhida por parte dos funcionários e principalmente do tabelião, um entusiasta, diga-se de passagem, pelos estudos da História, tendo inclusive publicado diversos trabalhos históricos nos jornais locais e um livro sob o nome de Histórias da História de Mogi das Cruzes.

c). - Cartório do Registro Civil das Pessoas Naturais. Localização Rua Dr. Paulo Frontin, 177. Serventuário: Diomar de Melo Freire. Data da instalação: 1630 .

E' êste o cartório mais antigo da comarca, estando seu arquivo perfeitamente organizado e sendo de fácil acesso, dada a cordialidade dos funcionários em geral e em particular do sr. Diomar de Melo Freire, sempre pronto a dar informações e a servir os interessados.

d) . - Cartório do Registro de Imóveis e Anexos. Localização: Rua Barão de Jaceguai, 174. Serventuário: Dr. José Odilon de Araújo. 
Oficial-Maior: Durval Afonso.

Data da instalação: 1874 .

Este cartório conta com duas partes distintas: o Registro de Imóveis e os Anexos. Esta última é composta por: Títulos e. documentos, Protestos e Júri.

Na parte do Registro de Imóveis, o primeiro documento. data de 22 de agôsto de 1874, no livro de transcrição, modêlo. n..$^{\text {4 }}$. Posteriormente o Livro de Transcrições, por lei de 1891 passou a ser o $n .^{\circ} 3$, iniciando com o registro $n .{ }^{\circ} 26$, de 29 de julho de 1891. Encontra-se atualmente no n. 3 bl. Arquivo. completamente organizado.

Na outra parte, no item referente aos Títulos e Documentos, o primeiro documento protocolado é de i2 ae abril de 1907, sendo êle uma procuração apresentada por Otacílio de Toledo.

No Júri, os processos passaram a ser arquivados nesse cartório a partir de 1895, sendo o primeiro processo do ano de 1894, estando indiciado Pascoal Júdice. E' êste um processo de recurso crime.

No tocante aos protestos é dificílimo indicar-se o primeir. ro documento, porque o valor de um protesto é por cinco anos, passados os quais cessa a validade, motivo pelo qual não se tem. a mesma facilidade de indicação.

O acesso à documentação é facilitada, existindo no cartório funcionários delicadíssimos, em especial a srta. Maria. Aparecida Rezende de Oliveira, que nos atendeu e não poupou. esforços para nos guiar através do cartório, nos apontando tôdà a documentação, muito bem conservada e corretamente organizada.

e) . - Cartório do Distribuidor, Contador, Partidor Judi-. cial e Avaliador Oficial da Comarca.

Localização: Rua José Bonifácio, 411.

Serventuário: Maurílio de Souza Leite.

Oficial Maior: Maurílio de Souza Leite Filho.

Escrevente habilitado: Marcos B. Souza Leite.

Os livros de registro e arquivo do cartório estão bem organizados e perfeitamente em dia.

$\mathrm{O}$ acesso ao arquivo é facilitado, sendo gentilíssimo o oficial maior, sr. Maurílio de Souza Leite Filho, sempre cordial e pronto atender todo aquêle que deseje informações a respeito de seus afazeres e do cartório. 


\section{VI. - MUSEU HISTÓRICO E PEDAGógICO VISCONDE DE MAUA'.}

Localização: Rua José Bonifácio, 141, 2. ${ }^{\circ}$ andar, sala 4. Data da instalação: 18 de fevereiro de 1959.

O Museu Histórico e Pedagógico Visconde de Mauá faz parte da rêde de Museus, criada e supervisionada pela Secretaria da Educação, sendo responsáveis pela organização do mesmo diversos membros, que compõe a Comissão Organizadora.

Os membros da Comissão Organizadora do Museu, apesar das dificuldades materiais que têm encontrado, principalmente na parte de mobiliário, tem realizado algumas leituras de documentos antigos, constantes dos arquivos sob sua guarda, esperando momento oportuno para a publicação dos mesmos.

Tôda e qualquer consulta é facilitada e os documentos existentes podem ser compulsados por todos quantos se interessem por assuntos históricos. A documentação está em ordem, faltando sòmente os fichários indispensáveis para uma organização perfeita. Consta dos arquivos do referido órgão documentos desde o século XVII.

\section{VII. - AGENCIA MUNICIPAL DE ESTATÍSTICA.}

Localização: Rua José Bonifácio.

Agente: Waldyr Pisciotta.

A Agência Municipal de Estatística foi fundada em 1938, tendo sido incorporada ao quadro do Instituto Brasileiro de Geografia e Estatística em 1940, quando passou a fazer parte da rêde nacional de agências estatísticas. Tôda e qualquer informação é dada, desde que não sejam solicitadas aquelas que por lei devem ser mantidas em sigilo. Os funcionários são atenciosos, não poupando esforços em bem servir.

VIII. - DIARIO DE MOGI.

Localização: Rua Barão de Jaceguai, 388.

Diretor: Tirreno Desambiagio.

Diretor-secretário: Jair da Costa Monsores.

Fundação: 13 de dezembro de 1957.

A redação do jornal mantém em ordem o arquivo do jornal, contendo todos os números já editados, até a data de hoje. A consulta ao arquivo do jornal é facilitada. 


\section{IX. - FONTES PARTICULARES.}

Cremos existir muitas outras fontes particulares, além das que citaremos neste item, mesmo porque sendo Mogi uma cidade bem antiga, devem ter as famílias mais tradicionais da terra guardados preciosos, que entretanto não pudemos localizar.

Entre outras citaremos: D. Josefina de Morais Melo, residente à rua José Bonifácio, 472, que possui em sua residência uma coleção quase completa do antigo jornal publicado neste município, o qual se intitulava 0 Liberal, que existiu entre os anos de 1931 e 1949, quando esta organização adquiriu bs direitos sôbre a então existente Fôlha de Mogi, jornal vespertino, inicialmente mimeografado, mas diário, ao contrário de O Liberal e a Gazeta de Mogi, jornais rue saíam sòmente aos domingos.

Do jornal Fôlha de Mogi, na sua primeira fase (mimeografada) segundo nos consta, sòmente existe uma coleção, conservada pelo seu antigo diretor e entusiasta dos estudos da história, sr. Isaac Grinberg, residente à Avenida Voluntário Fernando Pinheiro Franco, 410.

A única coleção de A Gazeta de Mogi, segundo pudemos apurar é ainda conservada pelo seu antigo diretor, sr. Carlos Alberto Lopes, residente à rua Afonso Pena, 57 .

Da Fôlha de Mogi, já na fase em que passou a pertencer à Emprêsa O Liberal (impressa), existiem alguns números conservados por seu antigo diretor, sr. Gilberto E. Servo, em sua tipografia, à rua Moreira da Glória, 53. Foi com pezar que nos falou o senhor Gilberto Servo do extravio da maior parte da coleção que fizera com cuidado, e que mandara encadernar para maior conservação, momento em que deixou de possuí-la.

\section{X. - PUBLICAÇõES SÔBRE MOGI DAS CRUZES.}

Encontramos na maior parte dos viajantes que percorreram o Brasil no século passado, relatos sôbre a cidade de Mogi das Cruzes, além de estudos feitos por historiadores de nossa éra, em que são incluídos diversos itens sôbre a terra fundada por Gaspar Vaz.

Mais especificamente pudemos tomar contacto com as publicaçōes que em seguida citamos: 

dores.

Almanaque de Mogi das Cruzes (1918), vários colabora-

Melo Freire, Manuel de Souza - Histórias da História de Mogi das Cruzes, 1958. São Paulo.

Ferreira (Emílio A.) - Mogy das Cruzes. Dados históricos e Notas Diversas. São Paulo, 1935.

Batalha (Jair Rocha) - Calhaus e Burgaus. São Paulo, 1958.

XI. - REVISTAS.

Revista Comemorativa do Aniversário de Mogi das Cruzes, n. ${ }^{\circ}$ especial, 1948. 1949 .

Revista Comemorativa do Aniversário de Mogi das Cruzes, 1950 .

Revista Comemorativa do Aniversário de Mogi das Cruzes,

Nestas revistas encontram-se dados históricos e indicações diversas sôbre a cidade de Mogi das Cruzes. Elaborada com o intuito de difundir as realizações do povo mogiano, já se constituem em precioso documento histórico, pois muitas das fotografias publicadas estampam prédios que não mais existem e logradouros que têm feição totalmente diversa nos dias atuais.

Estas revistas são fàcilmente encontradas, sendo que nós mesmos possuímos os números acima referidos.

\section{XII. - NOTAS COMPLEMENTARES.}

Além das fontes que indicamos dentro da sede da comarca, ainda podemos citar os seguintes cartórios de distrito:

1. - Cartório do Registro Civil de José Oliva de Melo, instalado no distrito de Biritiba Mirim em 1924.

2. - Cartório do Registro Civil de Wladimir de Ayrosa Flaquer, instalado no distrito de Braz Cubas, em 1954.

3. - Cartório do Registro Civil de Manuel de Freitas Garcia, instalado no distrito de Jundiapeba, em 1938.

4. - Cartório do Registro Civil de Erasto Pereira de Morais, instalado no distrito de Sabauna, em 1920. 
5. - Cartório do Registro Civil de Manuel de Almeida Prado, instalado no distrito de Taiaçupeba, em 1927.

Na cidade de São Paulo, no Arquivo do Estado, é encontrada farta documentação a respeito de Mogi das Cruzes, que já tivemos oportunidade de compulsar. E' realmente volumosa a documentação sôbre Mogi das Cruzes encontrada no Arquivo do Estado, além de ser valiosíssima.

Acreditamos ainda que se encontre muitos documentos referentes a Mogi das Cruzes nos municípios vizinhos de Santos, principalmente no Arquivo do Carmo de Santos, no município de Guararema, Suzano, Poá, Jacareí, Santa Isabel, Guarulhos, pois sendo êles limítrofes com a cidade de que nos ocupamos, devem reter em seus arquivos, pelo menos, relativa quantidade de documentos sôbre o município de que tratamos.

Esperamos que êste nosso pequeno e modesto trabalho, possa servir de guia para os historiadores que, em busca de documentos para a História do Brasil, venham a se interessar por Mogi das Cruzes e suas relações com o resto do país.

JOSE' SEBASTIÃO WITTER

Assistente da Cadeira de História da Civilização da Faculdade de Filosofia, Ciências e Letras de Rio Claro (Estado de São Paulo) 